\title{
PROTEÇÃO DA MULHER: DIREITO INDIVIDUAL E SOCIAL À IGUALDADE DE CONDIÇÕES NO MERCADO DE TRABALHO E AO DIREITO À MATERNIDADE
}

Grasiele Augusta Ferreira Nascimento

Pós-Doutora em Democracia e Direitos Humanos pela Universidade de Coimbra/ IGC; Doutora em Direito das Relações Sociais, sub-área Direito do Trabalho, pela Pontifícia Universidade Católica de São Paulo (PUC/SP); Coordenadora e Professora do Programa de Mestrado em Direito do Centro Universitário Salesiano de São Paulo (UNISAL); Professora Assistente Doutor da FEG/UNESP; Membro da Academia de Letras de Lorena (ALL).

Regina Vera Villas Bôas

Pós-Doutora em Democracia e Direitos Humanos pela Universidade de Coimbra/ IGC; Doutora em Direito das Relações Sociais, sub-área Direito Civil, pela Pontifícia Universidade Católica de São Paulo (PUC/SP); Professora do Programa de Mestrado em Direito do Centro Universitário Salesiano de São Paulo (UNISAL); Professora da Pontifícia Universidade Católica de São Pualo (PUC/SP).

\section{Resumo}

O papel da mulher na sociedade brasileira passou por significativas mudanças ao longo da história. Sua inserção e participação no mercado de trabalho foram marcadas por desigualdades em relação ao trabalho masculino, incluindo diversas formas de exploração e discriminação, como longas jornadas de trabalho, salários inferiores aos dos homens, maiores índices de desemprego e discriminação em relação à maternidade. Apesar da crescente evoluçáo do trabalho feminino e da adoçáo do princípio da igualdade pela Constituiçẫo Federal de 1988, os dados estatísticos ainda apontam significativas diferenças de oportunidades e de salários. O presente artigo objetivou realizar, a partir da legislação brasileira, um panorama sobre a condição atual do trabalho da mulher no Brasil, especialmente em relaçáo à proteção à maternidade. Conclui que o direito à maternidade inserido no rol constitucional dos direitos fundamentais sociais, protege, além da gestante, também o nascituro, ampliando assim o espectro da sua garantia legal.

\section{Palavras-chave}

Trabalho da mulher; Maternidade; Gênero; Igualdade de Direitos. 


\section{Abstract}

The role of women in Brazilian society has undergone significant changes throughout history. Their integration and participation in the labor market were marked by inequalities in relation to men's work, including various forms of exploitation and discrimination, as long working hours, lower wages than men, higher unemployment and discrimination related to maternity. Despite the growing trend of female labor and the adoption of the principle of equality by Federal Constitution of 1988, the statistics still indicate significant differences in opportunities and wages. This article aimed to perform, from the Brazilian legislation, an overview of the current condition of women's work in Brazil, especially in relation to maternity protection. Concludes that the right to maternity inserted in the constitutional role of fundamental social rights protects, apart from pregnant women, the unborn child as well, thus expanding the range of its legal guarantee.

\section{Key words}

Work of women; Motherhood; Gender; Equal Rights.

\section{Introdução}

O papel da mulher na sociedade brasileira passou por significativas mudanças ao longo da história.

Fruto de uma sociedade absolutamente patriarcal, a mulher era responsável pelo cuidado da família, da casa e da educação dos filhos, restando exclusivamente aos homens a responsabilidade pelo sustento do lar.

Com o passar do tempo, as mulheres começaram a ingressar no mercado de trabalho, reflexo das transformações demográficas, culturais e sociais vivenciadas no país.

Em relação às transformaçôes demográficas, podem ser citadas a queda da taxa de fecundidade, sobretudo nas cidades e nas regióes mais desenvolvidas do país, até atingir 2,1 filhos por mulher em 2005; a redução no tamanho das famílias que, em 2005, passaram a ser compostas por apenas 3.2 pessoas, em média, enquanto em 1992 tinham 3,7; o envelhecimento da população, com maior expectativa de vida ao nascer para as mulheres (75,5\% anos) em relação aos homens (67,9 anos); assim como o crescimento acentuado de arranjos familiares chefiados por mulheres os quais, em 2005, chegam a 30,6\% do total das famílias brasileiras residentes em domicílios particulares (BRUSCHINI, 2007, p. 540).

Segundo os dados do IBGE de 2012, em dez anos, de 2000 a 2010, o papel da mulher responsável pela família subiu de $22,2 \%$ para $37,3 \%$, e o tipo mais frequente entre as famílias conviventes é o formado pelas monoparentais femininas (53,5\%) (COSTA; 
MARRA, 2013, p. 1-2). Desta forma, a necessidade da participação das mulheres no setor produtivo também aumentou no decorrer dos anos, já que passou a ser responsável pela manutenção da família.

Contudo, embora seja crescente a participação das mulheres no mercado de trabalho e a diminuição das desigualdades entre homens e mulheres no Brasil, ainda é marcante a discriminação das mulheres no mercado de trabalho brasileiro, uma vez que enfrentam dificuldades não apenas no ingresso em um emprego, mas também na manutenção deste, além de que, ainda, auferem salários menores do que os homens. (A INSERÇÃO, 2013, p. 1).

O presente artigo tem como objetivo realizar, a partir da legislação brasileira, um panorama sobre a condição atual do trabalho da mulher, notadamente da mulher brasileira, revelando a situação vivida por ela, especialmente no que toca à proteção da maternidade.

\section{Proteção do Trabalho da Mulher no Brasil: Do Período Colonial ao Dias Contemporâneos}

Várias transformaçóes marcaram a presença da mulher no mercado de trabalho brasileiro, ao longo da história. Tanto que a maioria da mão de obra feminina do Brasil Colônia era da trabalhadora escrava, enquanto que as mulheres livres e brancas, oriundas de Portugal, faziam os serviços domésticos e dedicavam-se à maternidade.

Nesse período colonial as escravas realizavam atividades não só femininas, atuavam, também, na mineração, na extração das pedras preciosas, principalmente do ouro, no período denominado de ciclo do ouro (1807-1818), na panificação, alfaiataria e tecelagem.

A independência do Brasil foi proclamada em1822, sem modificar a situação do trabalho da mulher, já ignoradas pela Constituição Política do Império.

Embora sem direitos assegurados, o trabalho feminino começa a ser identificado, neste período, permanecendo ausente a regulamentação legislativa até o momento em que surge o emprego de máo de obra assalariada na indústria, e "desde então, se nota a divisão imposta pelo gênero ao trabalho" (CALIL, 2007, p. 23).

A Lei Áurea, assinada pela Princesa Isabel, em 1888, póe fim à escravidão e provoca uma verdadeira revolução na mão de obra, já que os trabalhadores se tornam livres e capazes de vender a sua força produtiva, selecionando o destinatário da sua venda. Logo em 1889, se percebe a falência do modelo político-econômico da monarquia, transformandose o Brasil em uma República. (CALIL, 2007, p. 24).

Observa-se, porém, que mesmo diante da libertação dos escravos, neste período, o número disponível de trabalhadores não era suficiente ao atendimento das fronteiras agrícolas, razão pela qual o Brasil começa a receber europeus para trabalharem no campo, os quais iniciavam aí os seus trabalhos, se dirigindo, logo após, às cidades, que começavam 
a se industrializar. A quantidade de ex-escravos e de imigrantes dirigidas para as cidades provocaram a aceleração do processo de urbanização de importantes cidades brasileiras, como é o caso do Rio de Janeiro, então, Capital Federal, e da cidade de São Paulo, fato que repercute na história dos trabalhadores pobres e das mulheres - abarcadas por estes trabalhadores-, influenciando a situação organizacional da família, eis que muitas delas estavam sendo chefiadas por mulheres, que sofriam, então, preconceitos porque trabalhavam fora e porque chefiavam sozinhas as suas famílias (CALIL, 2007, p. 26).

Uma coisa é certa: além dos inúmeros preconceitos enfrentados pelas mulheres, para elas eram reservados os menores salários, as maiores jornadas de trabalho e os trabalhos menos especializados e, apesar dos rumores de que, a partir de 1912, um novo Código do Trabalho entraria em vigor, regulamentando algumas situaçóes de trabalho feminino, entre outras, a possibilidade de contratação sem a autorização marital, a proibição de trabalho noturno e a limitação da jornada de trabalho, este Código nunca foi aprovado.

De fato, a primeira lei que promoveu direitos às mulheres foi a Lei paulista $n$. 1.596/1917, que ao instituir o Serviço Sanitário do Estado, proibiu o trabalho das mulheres em estabelecimentos industriais no último mês de gravidez e no primeiro puerpério. Já, na esfera federal, o Regulamento do Departamento Nacional de Saúde Pública, Decreto n. 16.300/1923, possibilitou às empregadas de estabelecimentos comerciais e industriais, um descanso de trinta dias anteriores e mais trinta dias posteriores ao parto. (CALIL, 2007, p. 28).

A criação da Organização Internacional do Trabalho (OIT), em 1919, faz surgir a interpretação de que a manutenção da paz mundial e a universalização das leis trabalhistas eram necessárias e importantes, criando-se, na sequência, várias Convençóes da Organização Internacional do Trabalho, com a finalidade de promoção da igualdade das condiçóes de trabalho, várias delas ratificadas pelo Brasil, na qualidade de país membro e fundador.

Lembra-se que foram dedicadas às mulheres, as Convençóes nos 3 e 4 , que diziam respeito à licença remunerada compulsória de seis semanas anteriores e posteriores ao parto, e de dois intervalos para a amamentação, além da proibição do trabalho noturno da mulher nas indústrias públicas ou privadas. Também, foram publicados, no período, a Decreto n. 21.417/1932, que regulamentou o trabalho da mulher nos estabelecimentos industriais e comerciais, estabelecendo importantes regras e direitos, como: a) a proibição do trabalho noturno, em subterrâneos, nas mineraçóes em subsolo, nas pedreiras, em obras de construção pública e nas atividades perigosas e insalubres; b) a garantia da liberdade salarial para o trabalho de igual valor, sem distinção de sexo; c) a garantia da proteção da maternidade.

Quanto a essa última garantia citada, a da proteção da maternidade, extrai-se relevantes direitos que foram, então assegurados às trabalhadoras, entre os quais: 1) o descanso obrigatório de quatro semanas anteriores e posteriores ao parto, podendo cada período ser aumentado em duas semanas, nas situaçóes excepcionais e mediante atestados por mé- 
dico; 2) descanso de duas semanas à empregada que sofresse o aborto não-criminoso; 3) dois intervalos diários, de meia hora cada um, nos primeiros seis meses de vida da criança, para o seu aleitamento, devendo os estabelecimentos - que contassem com mais de trinta empregadas de idade acima de dezesseis anos - ter um local apropriado para referido aleitamento; 4) durante o afastamento, o auxílio referente à metade da média auferida dos últimos seis vencimentos, pagos pelas caixas do Instituto de Seguridade Social e, na falta destas, pelo empregador, assegurando à mulher o retorno às suas funçóes e o direito de romper o seu contrato de trabalho, nas situaçôes em que a função exercida fosse prejudicial à gravidez; 5) proibido do trabalho feminino nos serviços perigosos ou insalubres; 6) proibido ao empregador demitir mulher grávida por esse motivo.

Várias das Constituições da República Federativa do Brasil protegeram o trabalho feminino, como é o caso da Carta Constitucional de 1934, promulgada em fase da industrializaçáo do Brasil, a qual promoveu o início da igualdade de salário entre homens e mulheres, o direito à jornada diária máxima de oito horas de trabalho, as férias anuais remuneradas, o descanso semanal, a proibiçáo de trabalho da mulher em atividades insalubres, assistência médica e sanitária à gestante, a licença-maternidade e o salário-maternidade.

Já, o mesmo não se pode dizer da Constituição da República Federativa do Brasil de 1937 - marcada por Estado intervencionista e decorrente do golpe de Estado do Presidente Getúlio Vargas -, que institui por lei o sindicato único e o imposto sindical, proibindo a greve e o "lockout". Referida Constituição elimina a garantia do emprego à gestante e a igualdade salarial entre homens e mulheres, permitindo a publicação do Decreto-lei n. 2.548/1940, o qual permite a reduçáo do salário das mulheres em até $10 \%$ do salário dos homens.

Entre às Constituiçóes de 1937 e 1946 surge a Consolidaçáo das Leis do Trabalho (CLT) de 1943, que dedica um capítulo ao trabalho da mulher (Capítulo III do Título III), estabelecendo regras quanto à proteçấo, à duração e às condiçôes do seu trabalho, tratando do trabalho noturno, dos períodos de descanso, dos métodos e locais de trabalho, da maternidade e das penalidades no âmbito laboral.

A Carta Constitucional de 1946 rompeu com o corporativismo existente, manteve os direitos trabalhistas protegidos e assegurou novos direitos trabalhistas, como o de assistência aos desempregados, de garantia do direito de greve e da participação nos lucros das empresas, muitos deles mantidos pela Constituição de 1967 e pela Emenda Constitucional $n^{\circ} 1 / 69$.

\subsection{Proteção do Trabalho da Mulher e a Constituição da República Federativa de 1988}

A vigente Constituição da República Federativa do Brasil assegurou a igualdade, pelo menos no plano formal, entre homens e mulheres. No tocante aos direitos traba- 
lhistas modificou referido cenário, diferenciando entre homens e mulheres somente para igualar a efetivação dos seus direitos no plano material, como é o caso da maternidade e, também, da possibilidade de realização do trabalho noturno pela mulher.

$\mathrm{O}$ artigo $6^{\circ} \mathrm{da}$ Carta Constitucional institui a proteção à Maternidade, situando-a no rol dos direitos sociais fundamentais, o que permite ser ela considerada como cláusula pétrea, a ser utilizada, notadamente em proveito dos direitos da gestante e do nascituro, cabendo ao Estado instituir medidas protetivas de referidos direitos.

Nesse sentido, se dirige a doutrina do Ministro Gilmar Mendes (2012, p. 192), ao relatar que os direitos sociais significam cláusulas pétreas, revestidas da imutabilidade, afirmando que

Há polêmica quanto a saber se além dos direitos individuais, expressamente referidos no art. $60, \$ 4^{\circ}$, da CF, também, os direitos sociais estariam protegidos como cláusula pétrea. De um lado, nega-se que os direitos sociais participem do rol dos limites materiais ao poder de reforma, argumentando-se que aquele dispositivo da Lei Maior fala em 'direitos e garantias individuais' e não em direitos fundamentais, gênero de que tanto os direitos individuais como os sociais são espécies.

(...) No Título I Da Constituição (Dos Princípios Fundamentais) fala-se na dignidade da pessoa humana como fundamento da República e essa dignidade deve ser compreendida no contexto também de outras normas do mesmo Título, em que se fala no valor social do trabalho, em sociedade justa e solidária, em erradicação da pobreza e marginalização e em redução de desigualdades sociais. Tudo isso indica que os direitos fundamentais sociais participam da essência da concepção de Estado acolhida pela Lei Maior. Como as cláusulas pétreas servem para preservar os princípios fundamentais que animaram o trabalho do constituinte originário e como este, expressamente, em título específico da Constituição, declinou Tais princípios fundamentais, situando os direitos sociais como centrais para a sua ideia de Estado democrático, os direitos sociais não podem deixar de ser considerados cláusulas pétreas.

Outras novidades trazidas pela Carta de 1988 estáo localizadas nos textos dos artigos $7^{\circ}$ ao $11^{\circ}$, notadamente no que diz respeito ao trabalho feminino, entre as quais, se destaca: a) redução da jornada de trabalho para 44 horas semanais; b) obrigatoriedade do regime do FGTS (Fundo de Garantia por Tempo de Serviço) e extinção da estabilidade decenal; c) incentivo à negociação coletiva e valorização do direito coletivo do trabalho; d) indenização na rescisão arbitrária do contrato de trabalho; e) aumento do adicional de horas extras, que passou a ser de, no mínimo, $50 \%$ sobre o valor da hora normal de trabalho; f) pagamento de adicional de $1 / 3$ na remuneração das férias; g) salário-família pago em razão do dependente do trabalhador de baixa renda nos termos da lei; h) proteção ao mercado de trabalho da mulher, mediante incentivos específicos, nos termos da lei; i) 
cento e vinte dias de licença-maternidade, sem prejuízo do emprego e do salário; j) cinco dias de licença-paternidade; k) assistência gratuita aos filhos e dependentes desde o nascimento até 5 (cinco) anos de idade em creches e pré-escolas; l) proibição da diferenciação dos salários, no que toca ao exercício das funções e nos critério de admissão relacionados ao sexo, cor, idade ou estado civil.

\section{Garantias do Trabalho da Mulher: Normas Jurídicas Nacionais de Prote- ção Contra a Discriminação no Trabalho, da Igualdade Salarial e da Pro- teção Física}

\subsection{Proteção da Mulher Contra Discriminação no Trabalho}

Além da legislação trabalhista que contempla inúmeros dispositivos que afastam critérios discriminatórios relacionados às relaçóes de trabalho, tem-se o artigo $5^{\circ}$ da vigente Constituição da República Federativa do Brasil que estabelece o princípio da igualdade, garantindo aos "brasileiros e aos estrangeiros residentes no País a inviolabilidade do direito à vida, à liberdade, à igualdade, à segurança e à propriedade"; e o artigo 70 que assegura a igualdade de direitos entre os trabalhadores urbanos e rurais, proibindo no inciso XXXI a discriminação de salário e de critérios de admissão do trabalhador que porta deficiência, e no inciso XXXII, a discriminação entre os trabalhos manual, técnico e intelectual. Também, o inciso XX, do mesmo artigo, se referindo ao trabalhador urbano e rural, dispóe sobre "a proteção do mercado de trabalho da mulher, mediantes incentivos específicos, nos termos da lei". E nesse sentido, a Lei no 9.799/1999 acrescenta à CLT, entre outros, o artigo 373-A que dispóe:

Ressalvadas as disposições legais destinadas a corrigir as distorçôes que afetem o acesso da mulher ao mercado de trabalho e certas especificidades estabelecidas nos acordos trabalhistas, é vedado: I - publicar ou fazer publicar anúncio de emprego no qual haja referencia ao sexo, à idade, à cor ou situaçáo familiar, salvo quando a natureza da atividade a ser exercida, publica e notoriamente, assim o exigir; II - recusar emprego, promoção ou motivar a dispensa do trabalho em razão de sexo, idade, cor, situaçáo familiar ou estado de gravidez, salvo quando a natureza da atividade seja notória e publicamente incompatível; III - considerar o sexo, a idade, a cor ou situação familiar como variável determinante para fins de remuneração, formação profissional e oportunidades de ascensão profissional; IV - exigir atestado ou exame, de qualquer natureza, para comprovação de esterilidade ou gravidez, da admissão ou permanência no emprego;

$\mathrm{V}$ - impedir o acesso ou adotar critérios subjetivos para deferimento de inscrição ou aprovação em concursos, em empresas privadas, em razão de sexo, idade, situação familiar ou estado de gravidez; VI - proceder 
o empregador ou preposto a revistas íntimas na empregadas ou funcionárias; Parágrafo único - $\mathrm{O}$ disposto neste artigo não obsta a adoção de medidas temporárias que visem ao estabelecimento das políticas de igualdade entre homens e mulheres, em particular as que se destinam a corrigir as distorções que afetam a formação profissional, o acesso ao emprego e as condiçóes gerais de trabalho da mulher.

Ainda, a respeito do citado artigo, seu caput apresenta texto que restringe as medidas discriminatórias, como dispóem as ressalvas I: " Disposiçóes legais destinadas a corrigir as distorçóes que afetam o acesso da mulher ao mercado de trabalho"; item II - "Certas especificidades estabelecidas nos acordos trabalhistas".

As disposiçóes legais a que se refere a primeira ressalva podem já existir no ordenamento jurídico ou, ainda, poderão ser criadas. No primeiro caso, vale a ressalva como instrumento interpretativo em favor da proteção do trabalho da mulher, corrigindo distorçóes para o seu ingresso no mercado de trabalho. (SILVA, 2009, p. 33). Na segunda ressalva, se o legislador tivesse usado a expressão "negociação coletiva”, teria abrangido não apenas as situações dos acordos, mas também, as convenções coletivas de trabalho, razão pela qual necessário se realizar a leitura nesse sentido, porque protege com mais amplitude os direitos do trabalho da mulher.

Nas hipóteses de violação das proibições dos itens I e IV, o Sindicato e o Ministério Público do Trabalho podem promover açóes civis públicas, com a finalidade de corrigir irregularidades e pagamentos de indenizaçóes, tanto por dano moral como por dano material.

Em relação à admissão no emprego, a Lei no 9.029/95 proíbe a exigência de atestados de gravidez e esterilização, e outras práticas discriminatórias, para efeitos admissionais ou de permanência da relaçáo jurídica de trabalho. A referida lei protege a mulher contra a discriminação em razão da situação familiar, como a gravidez, assegurando o direito à readmissão, com todos os salários do período de afastamento ou a percepção em dobro da remuneraçáo do período de afastamento, corrigida monetariamente e com juros legais.

\subsection{Proteção da Igualdade Salarial}

$\mathrm{O}$ inciso XXX, do artigo $7^{\circ}$ da Carta Magna vigente, estabelece e assegura a não discriminação do trabalho da mulher em relação ao homem, no que toca ao pagamento de salários, ao exercício de funçóes e aos critérios de admissão ao trabalho, relacionados ao sexo, idade, cor ou estado civil, proibindo qualquer diferença, nesse sentido.

Também, o artigo 461 da CLT, assegura que "sendo idêntica a função, a todo trabalho de igual valor, prestado ao mesmo empregador, na mesma localidade, corresponderá igual salário, sem distinção de sexo, nacionalidade ou idade". 
Observa-se que o trabalho de igual valor é aquele realizado com igual produtividade (quantidade) e mesma perfeição técnica (qualidade na realização dos serviços), relativamente às pessoas, cuja diferença de tempo na função não seja superior a 02 (dois) anos (Súmula n. 6, II, do TST).

Nessa esteira, desde que exerçam trabalho de igual valor, a legislação nacional estabelece igualdade salarial para os trabalhadores do sexo feminino e masculino.

A Consolidação das Leis do Trabalho dispóe, ainda, a respeito do direito à igualdade salarial sobre a existência de quadro de carreira da Empresa, o qual deve homologado pelo Ministério do Trabalho e estabelecer as regras relativas aos cargos e salários.

\subsection{Proteção Relacionada à Condição Física da Mulher}

A legislação trabalhista nacional, em relação à condição física da mulher, dispóe em seu favor, no artigo 390 da CLT, que "ao empregador é vedado empregar a mulher em serviços que demande o emprego de força muscular superior a 20 quilos para o trabalho continuo e 25 quilos para o trabalho ocasional'. Porém, muito embora, se admita que o legislador tenha objetivado proteger a mulher a partir da sua característica física, uma parte da doutrina nacional entende que a legislação discriminou o trabalho da mulher. Nesse sentido, Sérgio Pinto Martins afirma que

deveriam ser exigidos limites ao trabalho da mulher em razão da sua complexidade física. Se a mulher tiver condiçôes físicas para trabalhar em serviços pesados, não deverá ser proibida de fazê-lo, salvo se lhe prejudicar a saúde. De modo geral, a mulher só não deveria poder levantar pesos na fase de gestação, como a partir da $20^{\text {a }}$ semana, pois poderia prejudicar o feto, e em período logo após a concepção". (2012, p.327).

\section{Notas Relevantes sobre a Proteção da Maternidade no Direito Laboral Brasileiro}

Já foi dito, no presente trabalho que as normas referentes à maternidade objetivam proteger além da gestante, também o nascituro, criança fruto da protegida maternidade, no período entre a concepção e os primeiros meses de vida do filho. Ora, se destaca a licença da mãe adotiva, a estabilidade provisória e a licença da gestante, entre tantos outros direitos protegidos pela legislação nacional.

\subsection{Licença da Mãe Adotiva}

Conforme disposto no artigo 392-A da CLT, acrescentado pela Lei no 10.421/2002, todas as mães adotivas e as mulheres que recebem crianças de até oito anos de idade para guarda judicial, passam a ter o direito à licença-maternidade de cento e vinte dias, sem 
prejuízo do emprego e do salário, recebendo o pagamento do benefício previdenciário (salário maternidade) da Previdência Social, conforme regras fixadas pela Lei no 8.213/1991.

\subsection{Estabilidade Provisória}

$\mathrm{O}$ artigo 10, II, b, do ADCT assegura a estabilidade provisória da gestante, desde a confirmação da sua gravidez, até cinco meses após o parto, estabelecendo que "fica vedada a dispensa arbitrária ou sem justa causa da empregada gestante, desde a confirmação da gravidez até cinco meses após o parto". O legislador impôs à empregada gestante a obrigaçáo de confirmar formalmente ao empregador, a sua a gestação, por meio da entrega de exame ou atestado médico, garantindo à empregada a dispensa arbitrária, sem justa causa, por parte do empregador. Contudo, a redação da Súmula 244 do TST, vem alterar o entendimento de referido artigo, dispondo que

\section{Súmula 244 do TST - GESTANTE. ESTABILIDADE PROVISÓ- RIA (redaçáo do item III alterada na sessáo do Tribunal Pleno rea- lizada em 14.09.2012) - Res. 185/2012, DEJT divulgado em 25, 26 e 27.09.2012}

I - O desconhecimento do estado gravídico pelo empregador não afasta o direito ao pagamento da indenização decorrente da estabilidade (art. 10, II, "b" do ADCT).

II - A garantia de emprego à gestante só autoriza a reintegração se esta se der durante o período de estabilidade. Do contrário, a garantia restringe-se aos salários e demais direitos correspondentes ao período de estabilidade.

III - A empregada gestante tem direito à estabilidade provisória prevista no art. 10, inciso II, alínea "b", do Ato das Disposiçôes Constitucionais Transitórias, mesmo na hipótese de admissão mediante contrato por tempo determinado.

Referida afirmação, de que "o desconhecimento do estado gravídico pelo empregador não afasta o direito ao pagamento da indenização decorrente da estabilidade”, desprezou a exigência da confirmação da gravidez, nos termos do artigo 10, II, $b$, do ADTC, e adotou a aplicação da responsabilidade civil objetiva na situação em referência, ou seja, é suficiente a existência do estado gravídico à segurança da estabilidade da gestante, independentemente do conhecimento do empregador, de onde se conclui que havendo dispensa da empregada grávida, mesmo na hipótese do empregador desconhecer seu estado gravídico, a dispensa será considerada nula.

\subsection{Licença da Gestante}

A licença-gestante é custeada pela Previdência Social, sem ônus para o empregador, mas, apesar disso, "ainda hoje existem defensores de que a maternidade é um empecilho para 
a contratação de mulheres em idade reprodutiva" (CALIL, 2007, p. 58), o que mostra o preconceito em relação ao trabalho feminino.

Conforme dispóe o art. 7o, XVIII, da Carta Magna a mulher trabalhadora tem direito de gozar cento e vinte dias de licença, sem prejuízo do emprego e do salário, por ocasião do parto, licença esta, concedida preferencialmente vinte e oito dias antes, até noventa e oito dias, após o parto. E, no caso da ocorrência do parto antecipado - fora do tempo previsto -, por motivos alheios à vontade da gestante, permanece o direito da trabalhadora de gozar os cento e vinte dias integrais de licença.

A Lei no 11.770/2009 instituiu o Programa Empresa Cidadã - a Administração Pública, direta, indireta e fundacional é autorizada por esta lei a instituir programa que garanta prorrogação da licença-maternidade para suas servidoras -, ampliando o período de licença-maternidade para cento e oitenta dias para as empresas. A adesão das empresas ao Programa é facultativa, e tal ampliação somente ocorrerá se a licença for pedida pela gestante, até o primeiro mês após o parto, o que revela duas condiçóes fundamentais para a prorrogação da licença-maternidade: a) condição objetiva que exige ser a empresa participante do programa "Empresa Cidadā"; b) condição subjetiva que exige que a mulher requeira a ampliação da licença até o primeiro mês após o parto.

A luta pela ampliação da licença-gestante foi iniciada pela Sociedade Brasileira de Pediatria, que entendia que a convivência entre máe e filho pela amamentação da criança era de extrema importância à saúde física e psíquica da criança. Então, analogicamente, o benefício da ampliação da licença é garantido, na mesma proporção, à empregada que adote ou tenha a guarda judicial da criança, a teor do artigo $1^{\circ}$, parágrafo $2^{\circ}$, da Lei $n^{\circ}$ 11.770/2008. Impedida a trabalhadora, porém, no período da prorrogação da licença, de exercer atividade remunerada, e de colocar o filho recém-nascido em creches ou instituiçôes escolares que deles possam cuidar. Lemba0se que o valor pago à essa mãe trabalhadora, no período da prorrogação da licença é será integralmente descontado das parcelas do Imposto de Renda da empresa empregadora, conforme redação do artigo $5^{\circ}$ da lei $n^{\circ}$ 11.770/2008 que dispóe " A pessoa jurídica tributada com base no lucro real poderá deduzir o imposto devido, em cada periodo de apuração, o total da remuneração integral da empregada pago nos 60 (sessenta) dias de prorrogação de sua licença-maternidade, vedada a deduçâo como despesa operacional".

\section{Conclusões}

Percebe-se pelos presentes estudos, que o papel desenvolvido pela mulher contemporânea, na sociedade brasileira - o que se pode ampliar para a grande maioria dos países, cuja língua tem a mesma origem da nacional - se amplia com relação à família e ao mercado de trabalho, passando, assim, por significativas modificaçóes, ao longo dos anos, 
lembrando que as famílias, notadamente as brasileiras, não mais correspondem ao modelo único de família nuclear, formada por casal heterossexual e seus filhos.

As transformaçóes culturais colocam a mulher participando de maneira intensa no mercado de trabalho, aumentando sobremaneira as suas tarefas, tanto domésticas, como as de cuidado com a prole, como as do trabalho social. Ganha a mulher um novo papel social, revestido de enormes responsabilidades individual, familiar e social, o que lhe impóe mudança de comportamentos e disputa de cargos e funçóes no mercado de trabalho, junto aos homens e aos seus pares. Nesta luta, a mulher sofre inúmeras discriminaçóes, no mercado de trabalho, marcadas, notadamente, pelo salário, cargos ocupados e tratamento que lhe é dado, ocupando muitas vezes posição inferior ao homem, devido à sua situação de "ser mulher".

Nesse sentido, o presente estudo mostra que um dos principais fatores que favorece a discriminação da mulher no trabalho é a condição da mulher em relação à maternidade, situação esta, que muito embora não direcione o ônus de pagar o período da licençagestante à empresa empregadora, faz com que se sinta indiretamente prejudicada pelo afastamento da trabalhadora, apesar de serem os custos do empregador relacionados à contratação das mulheres muito reduzidos, fato que não justifica as desigualdades entre homens e mulheres.

No sentido do equilíbrio do estabelecimento das igualdades formal e material e dos deveres e direitos dos homens e das melhores, lembra-se o texto do artigo 227 da carta Magna dispóe "é dever da família, da sociedade e do Estado" assegurar proteção integral às crianças e aos adolescentes. A família, neste contexto, certamente envolve ambos os progenitores, da mesma maneira como os direitos trabalhistas abarcam as situaçóes de da maternidade e da paternidade.

Por derradeiro, apesar da evolução crescente dos direitos da mulher trabalhadora, no ordenamento nacional, ainda é necessária a realização de enorme mudança cultural que garanta direitos de parentalidade às mulheres e homens, seguida das responsabilidades familiares, garantindo-se às mulheres, também, o efetivo cumprimento dos seus direitos, já conquistados em relação à igualdade salarial, as condiçóes e tratamentos igualitários entre homens e mulheres no trabalho.

Tal qual a Constituição da República Federativa do Brasil, a Constituição Espanhola reconhece, no seu artigo 35, o direito de igualdade salarial e a não discriminação do trabalho da mulher em relação ao trabalho dos homens, o que é expressamente prevista no artigo $5^{\circ}$ da Lei Orgânica Espanhola (de março/2007) e, também, no artigo 28 do Estatuto dos Trabalhadores, que dispõe "El empresario está obligado a pagar por la prestación de un trabajo de igual valor la misma retribución, satisfecha directa o indirectamente, y cualquiera que sea la naturaleza de la misma, salarial o extrasalarial, sin que pueda 
producirse discriminación alguna por razón de sexo en ninguno de los elementos o condiciones de aquélla.". Referidos direitos, também, podem ser observados no âmbito europeu como direitos fundamentais, o que se extrai do artigo 157 do tratado de Funcionamento da União Europeia (antigo artigo 141 do TCE), das diretivas comunitárias (D 75/117/ CEE; D 79/7/CEE do Conselho; D 86/613/CEE; DC 92/85/CEE; D 2002/73/CE, D 2006/54/CE); e do Artículo 23 de Carta dos "Derechos Fundamentales de la Unión Europea”, que destaca o trabalho de interpretação do Tribunal de Justiça da União Europeia que adota para os casos o conceito de igualdade "retributiva" 1 .

\section{Referências}

A INSERSÃO das mulheres nos mercados de trabalho metropolitanos e a desigualdade nos rendimentos. Disponível em: http://www.dieese.org.br/analiseped/2013/2013pedmulhermet.pdf. Acesso em: 8 ago. 013.

ANDREUCCI, Ana Cláudia Pompeu Torezan. Salário-maternidade à mãe-adotiva no direito previdenciário brasileiro. São Paulo: LTR, 2005.

ARAÚJO, Adriane Reis de; FONTENELE-MOURÃO, Tânia (Orgs.). Trabalho de mulher: mitos, riscos e transformaçôes. São Paulo: LTr, 2007.

AZEVEDO, Luiz Carlos de. Estudo histórico sobre a condição jurídica da mulher no direito luso-brasileiro desde is abis mil até o terceiro milênio. São Paulo: Revista dos Tribunais, 2001.

BELEZA, Teresa Pizarro. Direito das mulheres e da igualdade social: a construção jurídica das relaçôes de gênero. Coimbra: Almedina, 2010.

BELTRAN, Ari Possidonio. Direito do Trabalho e Direitos Fundamentais. São Paulo, LTr, 2002.

BERTONCINI, Mateus Eduardo Siqueira Nunes; TRIPPIA, Luciane Maria. Cotas para mulheres em conselhos diretores - uma realidade europeia factível e necessária para o Brasil? In: BERTONCINI, Mateus Eduardo Siqueira Nunes; MARTINEZ, ReginaCélia;

ANDRADE, Ronaldo Alves de. Direitos especiais e tutela das minorias na atividade empresarial Florianópolis: FUNJAB, 2013. p. 165-190. Disponível em: http://www. publicadireito.com.br/artigos/?cod=77932c2c6056e219. Acesso em 29 abr. 2014.

BRITO FILHO, José Cláudio Monteiro de. Discriminação no trabalho. São Paulo: LTr, 2002.

1 Igualdad salarial (disponível em: http://www.msssi.gob.es/ssi/igualdadOportunidades/iEmpleo/Igualdad_salarial/home_igualdad_salarial.htm) 
BRUSCHINI, Maria Cristina Aranha. Trabalho e gênero no Brasil nos últimos dez anos. Disponível em: www.scielo.br/pdf/cp/v37n132/a0337132.pdf. Acesso em: 17 abr. 2014.

CALIL, Léa Elisa Silingowschi. História do direito do trabalho da mulher: aspectos históricos-sociológicos do início da República ao final deste século. São Paulo: Ltr, 2000.

CALIL, Léa Elisa Silingowschi. Direito do Trabalho da mulher: a questão da igualdade jurídica ante a desigualdade fática. São Paulo: LTr, 2007.

CANOTILHO, José Joaquim Gomes Gomes. Estudos sobre Direitos Fundamentais, 1 ed. Brasileira, $3^{\text {a }}$ tiragem, 2a Ed. Coimbra: Revista dos Tribunais, 2008.

CANTELI, Paula Oliveira. O trabalho feminino no divâ: dominação e discriminação. São Paulo: LTR, 2007.

CARVALHO, Robert Carlon de; WOOD, Daniel Ricardo Augusto. Estabilidade da gestante, abuso do poder de direito e a Constituição Federal de 1988. Uma questão de legalidade ou dignidade? In: NASCIMENTO, Grasiele Augusta Ferreira Nascimento; LERENA, Mirta Glady; BARACAT, Eduardo Milléo. Direito do Trabalho Florianópolis : FUNJAB, 2013. p.203-229. Disponível em: http://www.publicadireito.com.br/artigos/?cod=37ecd27608480aa3. Acesso em 10 Abr. 2014.

COSTA, Florença Ávila de Oliveira; MARRA, Marlene Magnabosco. Famílias brasileiras chefiadas por mulheres pobres e monoparentalidade feminina: risco e proteção. Rev. bras. psicodrama, São Paulo, v. 21, n. 1, 2013 Disponível em <http://pepsic. bvsalud.org/scielo.php?script=sci_arttext\&pid=S0104-53932013000100011\&lng =pt\&nrm=iso $>$. acessos em 01 jun. 2014.

FRANCO FILHO, Georgenor de Sousa. Trabalho da mulher: homenagem a Alice Monteiro de Barros. São Paulo: Ltr, 2009.

GAMBA, Juliane Caravieri Martins; MONTAL, Zélia Maria Cardoso. Trabalho da mulher e a emenda constitucional n. 72/2013. Disponível em: http://www.publicadireito.com.br/artigos/?cod=7b72de504960bfce. Acesso em: 09 maio 2014.

GOLSDAL, Thereza Cristina. Discriminação da mulher no emprego. Curitiba: Gênesis, 2003.

GOMES, Dinaura Godinho Pimentel. Direito do Trabalho e dignidade da pessoa humana, no contexto da globalização econômica. São Paulo: LTr, 2005.

Igualdad salarial. Disponível em: http://www.msssi.gob.es/ssi/igualdadOportunidades/ iEmpleo/Igualdad_salarial/home_igualdad_salarial.htm. Acesso em: 07/jun/2015.

JAKUTIS, Paulo. Manual de estudo da discriminação no trabalho. São Paulo: LTr, 2006. 
La integración laboral de la mujer en España Disponível em: http://www.artehistoria. com/v2/contextos/13016.htm. Acesso em: 07/jun/2015.

LIMA, Lucas Barbalho de. A proteção à maternidade no Brasil: Estudo acerca dos avanços da proteção à maternidade e de questôes ainda não tuteladas pelo Direito do Trabalho brasileiro na Pós- Modernidade.

LIMA, Maria da Glória Malta Rodrigues Neiva de. A proteção da igualdade de gênero no ordenamento jurídico nacional e internacional e os mecanismos asseguratórios. Rev. TRT - 9a R. Curitiba a. 35, n.65, Jul./ Dez. 2010, p. 1-72. Disponível em: www. trt9.jus.br. Acesso em: 27 maio 2014.

LUZ, Alex Faverzani da; FUCHINA, Rosimeri. A evolução histórica dos direitos da mulher sob a ótica do direito do Trabalho. Disponível em: http://www.ufrgs.br/nucleomulher/arquivos/artigoalex.pdf. Acesso em: 27 maio 2014.

MARTINS, Sérgio Pinto. Direito do Trabalho. 30ª ed. São Paulo: Atlas, 2014.

NASCIMENTO, Grasiele Augusta Ferreira (org) Direito das Minorias: proteçáa e discriminação no trabalho. Campinas: Alínea, 2004

NASCIMENTO, Grasiele Augusta Ferreira. Proteção contra a discriminação da mulher na relação laboral. Lisboa: Chiado, 2015.

OLIVEIRA, Francisco Antonio. Comentários às súmulas do TST. 9a ed. São Paulo: RT, 2008.

PINHEIRO, Luana; GALIZA, Marcelo; FONTOURA, Natália. Novos arranjos familiares, velhas convençóes sociais de gênero: a licença-parental como política pública para lidar com essas tensôes. Rev. Estud. Fem., Florianópolis, v. 17, n. 03, dez. 2009. Disponível em <http://educa.fcc.org.br/scielo.php?script=sci_arttext\&pi$\mathrm{d}=\mathrm{S} 0104-026 \mathrm{X} 2009000300013 \& \mathrm{lng}=\mathrm{pt} \& \mathrm{nrm}=\mathrm{iso}>$. acesso em 29 maio 2014.

PIOVESAN, Flávia. Direitos Humanos e o Direito Constitucional Internacional. 6a Ed. São Paulo: Max Limonad, 2004.

PIOVESAN, Flávia. Direitos Humanos e Direito do Trabalho. Atlas: São Paulo, 2010.

PROTEÇÃO da maternidade. Notas da OIT. Trabalho e família. Disponível em: http:// www.oitbrasil.org.br/content/nota-4-prote\%C3\%A7\%C3\%A3o-da-maternidade-0. Acesso em: 12 maio 2014.

QUIRINO, Raquel. Trabalho da mulher no Brasil nos últimos 40 anos. Disponível em: files.dirppg.ct.utfpr.edu.br/ppgte/revistatecnologiaesociedade/rev15/r15_a5.pdf. Acesso em: 17 abr. 2014.

RAMOS, Daniela Peixoto. Pesquisas de usos do tempo: um instrumento para aferir as desigualdades de gênero. Revista Estudos Feministas. Florianópolis, vol 17, n. 3, 
set/dez 2009. Disponível em: www.scielo.br/pdf/ref/v17n3/v17n3a14. Acesso em: 01 maio 2014.

RAPOSO, Vera Lúcia. Os limites da igualdade: um enigma por desvendar: a questão da promoção da igualdade laboral entre os sexos. In: Questóes laborais, A. 11, no 23. Coimbra: Coimbra Editora, 2004. p. 42-80.

RETRATO das desigualdades de gênero e raça. Disponível em: www.ipea.gov.br. Acesso em: 01 maio 2014.

ROSA, Waldemir. Sexo e cor: categorias de controle social e reprodução das desigualdades socioeconômicas no Brasil. Dossiê retrato das desigualdades de gênero e raça. Revista Estudos Feministas, Florianópolis, vol 17, n. 3 set/dez 2009. Disponível em: www.scielo.br. Acesso em: 01 maio 2014.

SANTOS, Alberto Silva; ALVES, Aline Cristina. A flexibilização das normas trabalhistas e o impacto no acesso do mercado de trabalho pelas mulheres. Qual o papel dos Direitos Humanos? In: GUIMARÃES, Antônio Marcio da Cunha; GOMES, Eduardo Biachi; LEISTER, Margareth Anne. Florianópolis : FUNJAB, 2013. p. 226-291. Disponível em: http://www.publicadireito.com.br/artigos/?cod=7fc346397dc20225. Acesso em: 10 abr. 2014.

SILVA, Antônio Álvares da. Trabalho da mulher e do menor. In: FRANCO FILHO, Georgenor de Sousa. Trabalho da mulher: homenagem a Alice Monteiro de Barros. São Paulo: Ltr, 2009. Cap. 1, p. 21-73.

SOUZA, Ana Maria Viola; NASCIMENTO, Grasiele Augusta Ferreira (Orgs.). Direito e o Trabalho. Campinas: Alínea, 2009. Acesso em: 10 abr. 2014.

TÁRREGA. Maria Cristina Vidotte Blanco; MIRANDA, Carla. Trabalhadoras na reestruturação produtiva do capital: qual Direito? Disponível em: http://www.conpedi.org.br/manaus/arquivos/anais/campos/maria_cristina_tarrega_e_carla_miranda. pdf. Acesso em: 09 maio 2014.

TEODORO, Maria Cecília Máximo; SILVA, Lídia Marina de Souza e. Gravidez no emprego: reflexôes sobre a tendência global de proteção ao emprego e ao mercado de trabalho da mulher. In: NASCIMENTO, Grasiele Augusta Ferreira; MAISAILIDIS, Mirta Gladys Lorena Manzo de; SILVA, Lucas Gonçalves da. Direito do trabalho I. Florianópolis :FUNJAB,2013 p. 279-299. Disponível em: http:// www.publicadireito.com.br/artigos/?cod=0498b76a320aee7c. Acesso em: 10 Abr. 2014.

THOME, Candy Florencio. O princípio da igualdade de gênero e a participação das mulheres nas organizaçóes sindicais de trabalhadores. Sáo Paulo: Ltr, 2012. 
ZIMMERMANN, Silvia Maria; DOS SANTOS, Teresa Cristina Dunka Rodrigues; DE LIMA, Wilma Coral Mendes. O assédio moral e o mundo do trabalho. Disponível em: http://www.prt12.mpt.gov.br/prt/ambiente/arquivos/assedio_moral_texto. pdf. Acesso em 09 fev. 2014. 